\title{
Return to play guidelines after anterior cruciate ligament surgery
}

\section{G Myklebust, R Bahr}

\section{Doctors should question whether return to high level pivoting sports is in the athlete's best interest after ACL reconstruction}

hen can I play again,
Doc?" is the emotionally
charged, quintessential question asked by nearly every athlete after anterior cruciate ligament (ACL) injury. Invariably, the same question is one of the first asked by parents, team mates, coaches, and-in the case of the high profile athlete-the media. This implies that, to meet the expectations of the athlete and his/her surroundings, swift surgical intervention and accelerated rehabilitation becomes a priority. Therefore it is not surprising if the time to return to play is the standard by which orthopaedic surgeons measure themselves and are measured in sports circles.

Measured by this standard, sports medicine has made giant advances in ACL treatment programmes during the previous decades. We have progressed from open surgery to arthroscopic surgery, from extended casting to short term bracing, from conservative to accelerated rehabilitation programmes, and from long hospital stays to outpatient surgery. When an athlete is injured today, it is expected that arthroscopic surgery will take place a few weeks after injury, that rehabilitation is started immediately, and that the patient is able to return to sport in four to nine months. The "best" surgeons and physiotherapists are rumoured to return players even sooner.

\section{"Are there other criteria whereby we should measure treatment out- come than the time to return to sport?"}

Lost in the need to succeed and with the fear of defeat deeply embedded in our decision making processes, it is no wonder that we rarely ask: "Is it time to quit? Is it safe to return patients to pivoting sports? What are the long term results of our treatment programmes? Are there other criteria whereby we should measure treatment outcome than the time to return to sport?" Should we not consider the risks of a graft rupture or additional knee lesions and the likelihood of the development of early osteoarthritis (OA) when advising the athlete after the initial injury.

To better address these issues, we have searched the literature for follow up studies after ACL injury examining the rate of return to sport, the reinjury risk, and/or the prevalence of OA (see table 1 for details on search terms and procedures). We have included studies of patients treated non-operatively or with reconstructive surgery who have been followed from 4 to 14 years after the initial injury.

\section{RETURN TO SPORT AFTER ACL INJURY}

For athletes who wish to return to pivoting sports, the typical advice is an ACL reconstruction after 4-8 weeks when full range of motion is established and there is no joint swelling. ${ }^{1-3}$ The purpose of an ACL reconstruction is to give the athlete a mechanically stable knee and to reduce the risk of subsequent injury to the menisci and cartilage by reducing anteroposterior joint motion. ${ }^{4}$ A number of short term studies have shown good to excellent knee function after reconstruction, whether hamstrings $^{5-7}$ or patellar tendon ${ }^{8}$ grafts are used. ${ }^{7}$ The same studies also confirm that most patients $(65-88 \%)$ are able to return to sport within the first year. Thus it is fair to state that surgery is effective in allowing injured athletes to resume their sports career.

Also, some athletes are able to return to high level pivoting sports without surgery. Among patients treated nonoperatively, the return rate ranges from $19 \%$ to $82 \%$ (table 1 ). ${ }^{9}{ }^{10}$ The athletes who successfully return to sport after non-operative treatment probably represent a selected group with functionally stable knees and a strong motivation to continue pivoting sport despite their injury. ${ }^{11}$

If athletes can return to sport with or without ACL reconstruction, how long are they able to keep playing after the initial injury? Most studies deal with ACL reconstructed patients, and the results vary between studies with a range from $8 \%$ to $82 \%$ (table 1 ). However, it is not always clear whether the authors are reporting an initial return rate or the proportion still playing at the time of follow up. ${ }^{12}$

Nevertheless, a few studies may be of particular interest, because they follow sports specific patient populations and report data on patients treated with and without surgery. Also, these studies mainly include elite athletes who can be assumed to be well motivated to continue their sports career. Thus the data may provide a realistic estimate of what to expect after returning to sport after injury. Myklebust et $a l^{9}$ found in a 6-11 year follow up of ACL injured team handball players that $58 \%$ of the reconstructed players and $82 \%$ of the conservatively treated patients were able to return to their preinjury level.

In the 10-13 year follow up study with a mixed sport population, Fink et $a l^{13}$ found a $44 \%$ reduction in high risk sports participation in the surgically treated group compared with a 70\% reduction among the conservatively treated. In the longest follow up to date, von Porat et $a l^{14}$ showed that, after 14 years, $6 \%$ in the operatively treated group and $1 \%$ in the conservatively treated group were still playing soccer. However, from these studies it is not possible to determine whether the players retired because of the injury or whether the retirement rate was higher than can be expected. Clearly, athletes may quit for reasons unrelated to their knee injury.

In the only study in which the reduction in sport participation can be related to a control group, Roos et al ${ }^{10}$ reported on elite soccer players three to seven years after the ACL injury. They found that $30 \%$ were active in soccer after three years compared with $80 \%$ in an uninjured control population. In addition, they showed that, after seven years, none of the injured elite players were active regardless of the type of treatment. It seems fair to conclude that, although the initial return rate is high, regardless of treatment, previously injured athletes retire at a higher rate than athletes without previous ACL injuries. The reason for this may be that many of the athletes who return to sport experience significant knee problems, such as instability, reduced range of motion, and/or pain. ${ }^{9}$

\section{REINJURY RATE AFTER SURGERY}

One of the potential concerns with returning to sport is that the reinjury rate to the reconstructed ACL or to other structures (menisci, cartilage, or other ligaments) ${ }^{15} 16$ may be unacceptably high. ${ }^{17}$ Only few studies have examined 


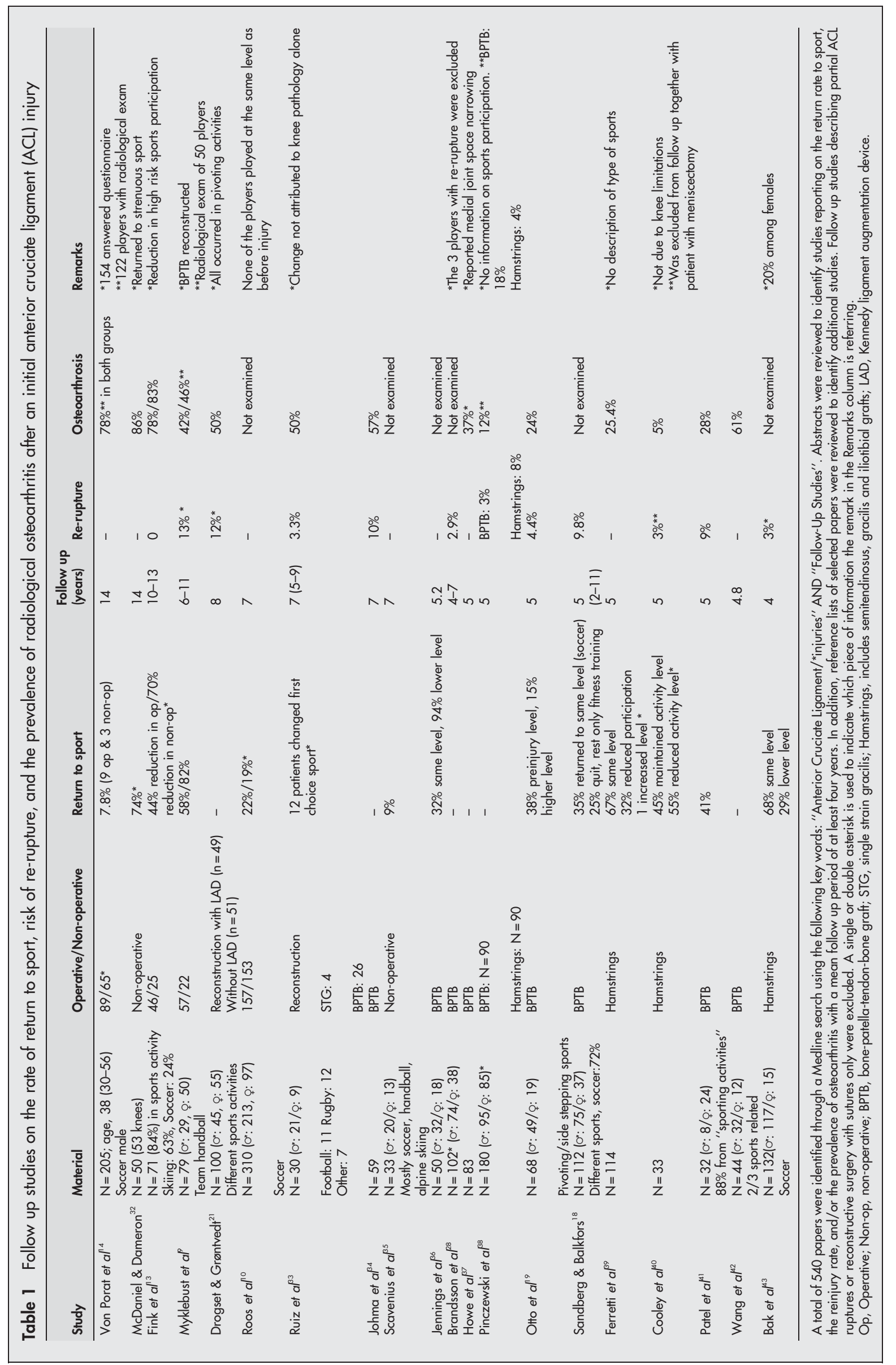

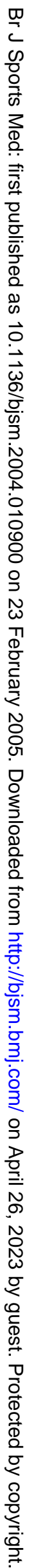


reinjury risk, and they report a wide range of rerupture rates ranging from $2.3 \%$ to $13 \%$ (table 1 ). ${ }^{18-20}$ The highest ACL rerupture risk (13\%) was found by Myklebust et $a l^{9}$ in their study of team handball players. However, one reason for the high risk seen in this study may be that team handball in itself is a high risk sport. Six of the 50 players who returned to team handball (9\%) experienced an ACL tear in their contralateral, previously uninjured knee during the observation period. ${ }^{9}$ A similar reinjury rate was reported by Drogset and Grøntvedt, ${ }^{21}$ who found that $12 \%$ of their patients suffered a reinjury during an eight year follow up period, all during pivoting sports.

However, these results, as well as studies reporting lower rerupture rates, must be interpreted with caution. Firstly, the population at risk is not known, because it clearly depends on the proportion returning to sport and the number of years they continued to play. Secondly, bias must be considered when there is a significant loss to follow up as is evident in most of the studies. Thus, we do not know if there is an increased risk of reinjury to the reconstructed ACL compared with a healthy knee, nor do we know the rate of meniscus or cartilage injury associated with return to sport. Nevertheless, it is clear that nearly all of the reruptures reported in the papers shown in table 1 occurred while pivoting sports were being played.

\section{"Returning to pivoting sport without a reconstruction results in consider- able risk of injury to the menisci and cartilage"}

Further damage to the knee with continued sports participation is of course also a concern in non-operatively treated patients. Myklebust et a ${ }^{9}$ showed that $22 \%$ of the non-operatively treated players who returned to sport underwent additional surgery for an injured meniscus compared with 12\% in the operatively treated players. Returning to pivoting sport without a reconstruction results in considerable risk of injury to the menisci and cartilage.

\section{PREVALENCE OF OA}

Using the rate of return to sports or even the reinjury risk as measures of treatment success may be grossly misleading. An ACL injury entails a significant risk of $\mathrm{OA}^{, 2}$ and it may be that the initial injury itself is an important determinant of the development of OA, no matter what treatment is used or how the knee is loaded during subsequent years.

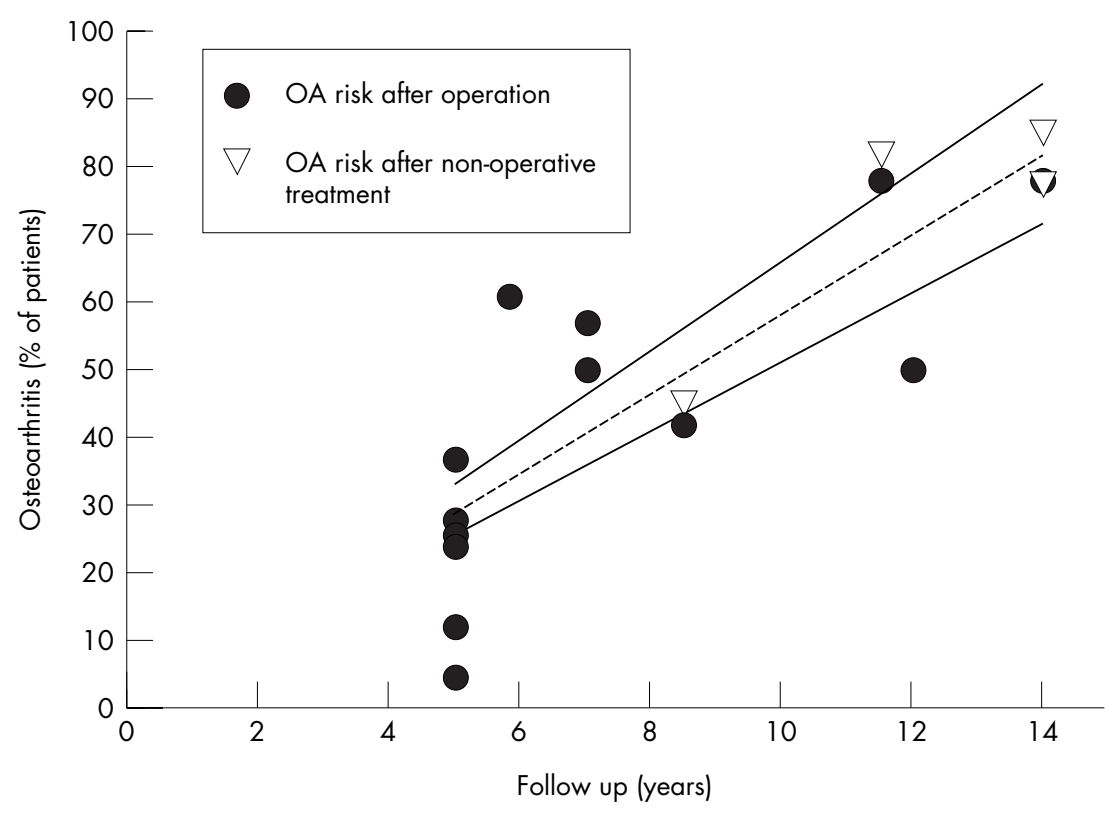

Figure 1 Anterior cruciate ligament (ACL) follow up studies and osteoarthritis $(\mathrm{OA})$ prevalence. $O A$ risk after both reconstructive surgery with bone-patella-tendon-bone graft or hamstring graft and non-operative treatment is shown. The dashed line indicates the forced regression $(y=6.0 \mathrm{t} ; r$ $=0.85)$ between time $(t)$ and OA prevalence $(y)$, with the $95 \%$ confidence intervals shown by thin solid lines. Follow up studies describing partial $\mathrm{ACL}$ ruptures or reconstructive surgery with sutures only are omitted.

Another important factor is that isolated ACL injury is a rare occurrence. Bone bruises are evident in $80-90 \%$ of ACL injured knees, although their significance for future knee function is not clear. ${ }^{23}$ Meniscal injuries are found in $75 \%,{ }^{23}$ and loss of meniscal tissue is an important risk factor for future degenerative joint disease of the knee. Other structures such as ligaments and capsular tissues-for example, the posterolateral structures-are often injured and may contribute to future OA. Assuming that treatment of ACL injury by reconstructing the ACL with tendon, repairing articular cartilage injuries with procedures forming fibrocartilage, and suturing the meniscus restores the knee to normality may not be true. After ACL injury, the biochemical markers do not return to normal even after many years. ${ }^{24}$

Also, sports participation in itself, even without a history of injury, results in a moderate increase in the risk of hip and knee OA. ${ }^{25-27}$ Thus it seems reasonable to hypothesise that this risk would be exacerbated in a previously injured knee where joint motion and cartilage loading patterns are significantly different from the intact knee, despite proper rehabilitation or surgical intervention. ${ }^{28} 29$

Figure 1 shows the risk of developing radiological signs of OA with time after an ACL injury. After 10 years, approximately half of the patients display signs of OA. An extrapolation of these results indicates that nearly all patients will have OA after 15-20 years. A recent study showed that all athletes undergoing revision ACL surgery had OA when they were re-examined 37 (1258) months after the reoperation ${ }^{30}$ (because this study includes patients with two or more ACL injuries, it could not be included in fig 1 or table 1 ). It seems that a high frequency of radiographic changes is the rule rather than the exception after ACL injury.

These findings raise two important questions. Firstly, is there a difference in the risk of OA between surgically treated and non-operatively treated patients? Unfortunately, there are no prospective trials in which patients have been randomised to a reconstruction or non-operative treatment. In the three follow up studies that include surgically and non-operatively treated patients there may be a selection bias, which makes it difficult to interpret the results. Nevertheless, as shown in fig 1, the prevalence of OA does not seem to depend on whether an ACL reconstruction was performed or not. von Porat et $\mathrm{al}^{14}$ reported $78 \%$ OA prevalence in both groups after 14 years, Fink et al ${ }^{13} 78 \% v$ $83 \%$ after $10-13$ years, and Myklebust et $a l^{9} 42 \% \vee 46 \%$ after $6-11$ years. Thus there is no evidence to suggest that ligament reconstruction prevents future OA.

The second question is: is there an increased risk of $\mathrm{OA}$ in athletes who return to sports compared with those 
who choose to retire? For obvious reasons, there is no study in which athletes have been randomised to continued sports participation or early retirement. Furthermore, although it would have been interesting to compare OA prevalence between athletes who chose to retire and those who continued to play, these data have not been reported in the available studies. Therefore there is an urgent need to establish large prospective studies to follow cohorts of athletes with ACL injury. Using a multivariate approach, it will then be possible to assess the independent effects of treatment methods, associated injuries to the menisci and cartilage at the time of injury, graft choice, reinjuries, and continued sports participation, to mention a few factors that could be important for the development of early OA.

\section{TIME TO QUIT}

In 1970 Kennedy stated that "the ACL is the most common cause of the exathlete. ${ }^{\prime 31}$ In other words, the treatment offered at the time did not permit athletes to go back to sport. This is no longer the case, at least in the short term, thanks to major advances in surgical treatment and rehabilitation programmes. As shown above, most elite athletes are initially able to resume their sports career. However, the data also show that the retirement rate may be higher among athletes with a previous ACL injury compared with healthy athletes. Furthermore, it is apparent that there is a significant risk of reinjury to the graft, as well as the menisci and cartilage with continued sports participation. Finally, there are convincing data to show that nearly all patients will develop OA with time.

Thus it seems reasonable to question whether return to high level pivoting sports really is in the athlete's best interest-if long term knee health is the primary concern. The relevant issue that needs to be addressed is: what are the additional risks of further injuries and early $\mathrm{OA}$ associated with return to sport? We cannot answer this question properly from the available data. Until we can, as physicians and physiotherapists working with this patient group, it is our obligation to provide adequate information of the potential consequences of returning to pivoting sports. We must enable the athlete to make an informed decision with all necessary information available, including the caveats related to future risk of knee problems and OA. This includes clearly pointing out that ACL surgery can only be expected to improve knee stability, but that ACL surgery does little or nothing to secure a future healthy knee.
The answer to the question "When can I play again, Doc?" is straightforward and can be comfortably stated by most doctors: "Probably within 1 to 9 months depending on the treatment that is best for you ..." BUT let us take a moment to talk about the more difficult question I am going to ask you: "Should you return to sport?"

Br J Sports Med 2005;39:127-131.

doi: 10.1136/bjsm.2004.010900

\section{...... \\ Authors' affiliations}

G Myklebust, R Bahr, Oslo Sports Trauma Research Center, Norwegian University of Sport and Physical Education, Oslo, Norway

Correspondence to: G Myklebust, Oslo Sports Trauma Research Center, Norwegian University of Sport and Physical Education, Oslo, Norway; grethe.myklebust@nih.no

Competing interests: none declared

\section{REFERENCES}

1 Fox JA, Nedeff DD, Bach BR Jr, et al. Anterior cruciate ligament reconstruction with patellar autograft tendon. Clin Orthop 2002:53-63.

2 Haddad FS, Oussedik SI. Cruciate ligament reconstruction. Hosp Med 2004;65:412-17.

3 Grant JA, Mohtadi NG. ACL reconstruction with autografts, weighting performance considerations and postoperative care. Phys Sportsmed 2003:31:27-40

4 Fithian DC, Paxton LW, Goltz DH. Fate of the anterior cruciate ligament-injured knee. Orthop Clin North Am 2002;33:621-36.

5 Siegel MG, Barber-Westin SD. Arthroscopicassisted outpatient anterior cruciate ligament reconstruction using the semitendinosus and gracilis tendons. Arthroscopy 1998;14:268-77.

6 Gobbi A, Tuy B, Mahajan S, et al. Quadrupled bone-semitendinosus anterior cruciate ligament reconstruction: a clinical investigation in a group of athletes. Arthroscopy 2003; 19:691-9.

7 Feller JA, Webster KE. A randomized comparison of patellar tendon and hamstring tendon anterior cruciate ligament reconstruction. Am J Sports Med 2003;31:564-73.

8 Corry IS, Webb JM, Clingeleffer AJ, et al. Arthroscopic reconstruction of the anterior cruciate ligament. A comparison of patellar tendon autograft and four-strand hamstring tendon autograft. Am J Sports Med 1999;27:444-54.

9 Myklebust G, Bahr R, Engebretsen L, et al. Clinical, functional and radiological outcome 611 years after $A C L$ injuries in team handball players: a follow-up study. Am J Sports Med 2003;31:981-9

10 Roos H, Ornell M, Gardsell P, et al. Soccer after anterior cruciate ligament injury: an incompatible combination? A national survey of incidence and risk factors and a 7 -year follow-up of 310 players [see comments]. Acta Orthop Scand

1995;66:107-12

11 Eastlack ME, Axe MJ, Snyder-Mackler L. Laxity, instability, and functional outcome after $\mathrm{ACL}$ injury: copers versus noncopers. Med Sci Sports Exerc 1999;31:210-15.

12 Fitzgerald GK, Axe MJ, Snyder-Mackler L. The efficacy of perturbation training in nonoperative anterior cruciate ligament rehabilitation programs for physical active individuals. Phys Ther 2000;80:128-40.

13 Fink C, Hoser C, Hackl W, et al. Long-term outcome of operative or nonoperative treatment of anterior cruciate ligament rupture: is sports activity a determining variable? Int J Sports Med 2001;22:304-9.

14 Von Porat A, Roos EM, Roos H. High prevalence of osteoarthritis 14 years after an anterior cruciate ligament tear in male soccer players: a study of radiographic and patient relevant outcomes. Br J Sports Med 2004;38:263.

15 Aroen A, Loken S, Heir S, et al. Articular cartilage lesions in 993 consecutive knee arthroscopies. Am J Sports Med 2004;32:211-15.

16 Tandogan RN, Taser O, Kayaalp A, et al. Analysis of meniscal and chondral lesions accompanying anterior cruciate ligament tears: relationship with age, time from injury, and level of sport. Knee Surg Sports Traumatol Arthrosc 2004; 12:262-70.

17 Jones HP, Appleyard RC, Mahajan S, et al Meniscal and chondral loss in the anterior cruciate ligament injured knee. Sports Med 2003;33:1075-89.

18 Sandberg R, Balkfors B. Reconstruction of the anterior cruciate ligament. A 5-year follow-up of 89 patients. Acta Orthop Scand 1988;59:288-93.

19 Otto D, Pinczewski LA, Clingeleffer A, et al. Fiveyear results of single-incision arthroscopic anterior cruciate ligament reconstruction with patellar tendon autograft. Am J Sports Med 1998;26:181-8.

20 Bak K, Scavenius M, Hansen S, et al. Isolated partial rupture of the anterior cruciate ligament. Long-term follow-up of 56 cases. Knee Surg Sports Traumatol Arthrosc 1997;5:66-71.

21 Drogset JO, Grontvedt T. Anterior cruciate ligament reconstruction with and without a ligament augmentation device : results at 8-year follow-up. Am J Sports Med 2002;30:851-6.

22 Gillquist J, Messner K. Anterior cruciate ligament reconstruction and the long-term incidence of gonarthrosis. Sports Med 1999;27:143-56.

23 Engebretsen L, Arendt E, Fritts HM. Osteochondral lesions and cruciate ligament injuries. MRI in 18 knees. Acta Orthop Scand 1993:64:434-6.

24 Lohmander LS, Saxne T, Heinegard DK. Release of cartilage oligomeric matrix protein (COMP) into joint fluid after knee injury and in osteoarthritis. Ann Rheum Dis 1994;53:8-13.

25 Drawer S, Fuller CW. Propensity for osteoarthritis and lower limb joint pain in retired professional soccer players. Br J Sports Med 2001;35:402-8.

26 Shepard GJ, Banks AJ, Ryan WG. Exprofessional association footballers have an increased prevalence of osteoarthritis of the hip compared with age matched controls despite not having sustained notable hip injuries. $\mathrm{Br} J$ Sports Med 2003;37:80-1.

27 Kujala UM, Kettunen J, Paananen $\mathrm{H}$, et al. Knee osteoarthritis in former runners, soccer players, weight lifters, and shooters. Arthritis Rheum 1995;38:539-46.

28 Brandsson S, Faxen E, Kartus J, et al. A prospective four- to seven-year follow-up after arthroscopic anterior cruciate ligament reconstruction. Scand J Med Sci Sports 2001;11:23-7.

29 Lewek MD, Chmielewski TL, Risberg MA, et al. Dynamic knee stability after anterior cruciate ligament rupture. Exerc Sport Sci Rev 2003;31:195-200

30 Eberhardt C, Wentz S, Leonhard T, et al. Effects of revisional $A C L$ surgery in semi-professional athletes in "high-risk pivoting sports" with chronic anterior instability of the knee. J Orthop Sci 2000;5:205-9.

31 Fowler PJ, Snyder-Mackler L. Commentary J Orthop Sports Phys Ther 2001;31:661

32 McDaniel WJJ, Dameron TBJ. The untreated anterior cruciate ligament rupture. Clin Orthop 1983:158-63

33 Ruiz AL, Kelly M, Nutton RW. Arthroscopic ACL reconstruction: a 5-9 year follow-up. Knee 2002;9:197-200.

34 Johma NM, Pinczewski LA, Clingeleffer A, et al Arthroscopic reconstruction of the anterior cruciate ligament with patellar-tendon autograft and interference screw fixation. J Bone Joint Surg [Br] 199, 81:775-9.

35 Scavenius M, Bak K, Hansen S, et al. Isolated total ruptures of the anterior cruciate ligament: a clinical study with long-term follow-up of 7 years. Scand J Med Sci Sports 1999;9:114-19.

36 Jennings S, Rasquinha V, Dowd GS. Medium term follow up of endoscopically assisted BPTB $\mathrm{ACL}$ reconstruction using a two-incision 
technique: return to sporting activity. Knee 2003; 10:329-33.

37 Howe JG, Johnson RJ, Kaplan MJ, et al. Anterior cruciate ligament reconstruction using quadriceps patellar tendon graft. Part I. Long-term follow up. Am J Sports Med 1991;19:447-57.

38 Pinczewski LA, Deehan DJ, Salmon $\amalg$, et al. A five-year comparison of patellar tendon versus four-strand hamstring tendon autograft for arthroscopic reconstruction of the anterior cruciate ligament. Am J Sports Med 2002;30:523-36
39 Ferretti A, Conteduca F, De Carli A, et al. Osteoarthritis of the knee after ACL reconstruction. Int Orthop 1991;15:367-71.

40 Cooley VJ, Deffner KT, Rosenberg TD. Quadrupled semitendinosus anterior cruciate ligament reconstruction: 5-year results in patients without meniscus loss. Arthroscopy 2001;17:795-800.

41 Patel JV, Church JS, Hall AJ. Central third bonepatellar tendon-bone anterior cruciate ligament reconstruction: a 5-year follow-up. Arthroscopy 2000;16:67-70.
42 Wang CJ, Huang TW, Jih S. Radiographic assessment of the knee after patellar tendon reconstruction for anterior cruciate ligament deficiency. Chang Gung Med J 2004; 27:85-9

43 Bak K, Jorgensen U, Ekstrand J, et al. Reconstruction of anterior cruciate ligament deficient knees in soccer players with an iliotibial band autograft. A prospective study of 132 reconstructed knees followed for $4(2-7)$ years. Scand J Med Sci Sports $2001 ; 11: 16-22$

\section{Committee on Publication Ethics Seminar 2005 Friday 11 March 2005, 9.30 am - 5 pm, BMA House, London}

This year's seminar will focus on COPE's new Code of Conduct for Editors and interactive workshops on common ethical and editorial dilemmas. The seminar is for editors, authors, and all those interested in increasing the standard of publication ethics.

The Code aims to set a new basic standard for the ethical conduct of editors and sets out guidelines for quality and correcting the record, standing by decisions made, ethics committee approval, consent for publication confidentiality of submitted material, guidance to authors, pursuing misconduct, relationship to publishers, owners, and advertisers, and conflict of interest. The code also creates a mechanism to refer a complaint to COPE if an editor has breached the code.

The seminar will include:

- The new Code of Conduct for Editors

- Dr lona Heath, Chair BMJ Ethics Committee-research, audit, and ethics committee approval

- COPE's new website-full text and keyword searching for COPE's advice on specific issues, for example research misconduct, conflict of interest, and deception

- Interactive workshops-common ethical and editorial dilemmas for editors

- Opportunities to network with other editors and share your experiences and challenges

The seminar is free for COPE members and $£ 30.00$ for non-members. Numbers are limited and early booking is advisable. For registrations or more information please contact Sam Knottenbelt at cope@bmigroup.com or call 0207383 6602. For more information on COPE see www.publicationethics.org.uk/ 